\title{
The comparative effects of advance organizers vs textual enhancement on the acquisition of English passivization
}

\author{
A'lipour, Javad $\bowtie$ \\ University of Isfahan, Iran (alipour.edu@gmail.com) \\ Youhanaee, Manijeh \\ University of Isfahan, Iran (youhanaee_m@hotmail.com) \\ Barati, Hossein \\ University of Isfahan, Iran (h.barati@gmail.com)
}

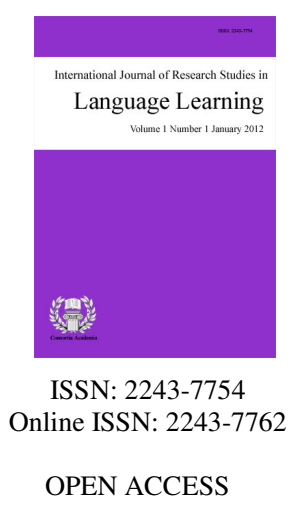

\section{Abstract}

The present study investigated the effectiveness of 3 types of grammar presentation on the acquisition of passive constructions. Eighty EFL Persian-speaking learners in 4 Iran Language Institute intact classes constituted the groups. One of the experimental groups was exposed to Intralingual advance organizers (Intra-AOs). The second group received Interlingual advance organizers (Inter-AOs), and the third group was presented with textually enhanced material. The results of the posttest indicated that there was a significant difference between all the groups, and that all the treatments were considerably effective. The inter-AO group outperformed the other groups on the posttest, and the intra-AO group came in second, outperforming the TE group. The findings of the study led us to conclude that the mother tongue may have provided the learners in the inter-AO group with sufficient backdrop that the learners drew on to make a substantial transition from the known to the unknown. Also, a case is made for viewing noticing as a multi-dimensional system which is more effective when links are created between and among the target structures than when one single textually enhanced item becomes the focus.

Keywords: advance organizers; grammar instruction; interlingual advance organizers (Inter-AOs); intralingual advance organizers (Intra-AOs); textual enhancement (TE) 


\section{The comparative effects of advance organizers vs textual enhancement on the acquisition of English passivization}

\section{Introduction}

A quick glance through the second language acquisition (SLA) literature suggests that grammar has taken a revived role. A number of reasons could be detected for this rising trend in the teaching and learning of grammar. Nassaji and Fotos (2004) enumerate a number of these reasons. They argue that the noticing hypothesis (Schmidt, 1990, 2001), the teachability hypothesis (Pienemann, 1984, 1988, 1999), and the inadequacy of meaning-focused approaches (Celce-Murcia, Dörnyei, \& Thurrell, 1997; R. Ellis, 1997, 2002b; Mitchell, 2000), along with the agreement among SLA researchers that instruction of grammar rules plays a key role in the process of second language acquisition (R. Ellis, 1985, 1990, 1994, 2001, 2002a; Larsen-Freeman \& Long, 1991; Long, 1983 , 1988,1991 ) could be some of the underlying reasons why the role of grammar has been reconsidered.

The Noticing Hypothesis (Schmidt, 1990, 1993, 2001) puts forth the idea that the acquisition of every aspect of a second language hinges on the existence of conscious attention. It must be noted that some SLA researchers have taken issue with this hypothesis (e.g. Truscott, 1998). However, most of them seem to agree that awareness of target forms is a prerequisite for learning (Doughty, 2001; Bygate, Skehan, \& Swain, 2001; Bialystok, 1994; Dekeyser, 1998; R. Ellis, 2001, 2002a; Basturkmen, \& Loewen, 2001a, 2001b; Fotos, 1993, 1994). The hypothesis is given further strength by research studies which indicate that language learners cannot afford to attend to both meaning and form simultaneously (Skehan, 1998; Tomasello, 1998).

A second reason for the change in our thinking towards the role of grammar concerns the teachability hypothesis developed by Pienemann (1994, 1998, \& 1999), which suggests that while certain developmental sequences are fixed and not influenced by instruction, there are structures which could be incorporated into instruction irrespective of when they are introduced. Based on this hypothesis, grammar instruction could conceivably engender positive results providing that it is in line with learners' developmental stage. The implication seems to be that grammar instruction ought to be an important component of language instruction, and the only caveat concerns assurance of developmental readiness on the part of the learners (Lightbown, 2000).

A third reason for the revival of grammar instruction is that exclusively meaning-focused approaches which place an overemphasis on fluency do so at the expense of a lack of attention towards grammar, and thus these approaches have turned out to be inadequate. It seems that in these contexts, it is often the case that grammar is not given its due. Research by Swain and her colleagues (Harley \& Swain, 1984; Lapkin, Hart, \& Swain, 1991; Swain, 1985; Swain \& Lapkin, 1989) bears this out. Their extensive research indicated that in spite of the fact that the learners had been exposed to a large bulk of input in French immersion programs, they still fell short of being accurate in a number of grammatical forms. The implication of their research is that grammar should assume a more prominent role in second language teaching and learning.

Given the current importance attached to grammar, whether grammar instruction should be a component of language teaching is not much of an unanswered question. The question is rather what techniques would best be fitted to a communicative context, and lead to acquisition in learners. In this research study, two of the techniques that look potentially effective were compared; textual enhancement and advance organizers. A brief review of the research findings on these two methods is provided below.

\subsection{Textual Enhancement}

Many approaches to second language acquisition subscribe to the view that instruction should be delivered 
The comparative effects of advance organizers vs. input enhancement on the acquisition of English passivization

in such a fashion that it provides learners with input and allows for opportunities of meaningful interaction. However, input alone does not necessarily lead to higher levels of accuracy (Harley \& Swain, 1984). A number of researchers have suggested that second language learners be exposed to consciousness-raising activities (Sharwood Smith, 1981) aimed at drawing learners' attention to input that may otherwise go unnoticed. Sharmwood Smith (1991) then went on to propose that the term consciousness-raising be replaced by input enhancement. This is also supported by Schmidt's noticing hypothesis (2001) which offers reasons as to its effectiveness. He argues that in order for input to be processed, it must first be noticed.

SLA research has been pursuing the establishment of effective means of drawing learners' attention to grammatical features. While the effects of explicit instruction cannot be ignored, implicit instruction including textual enhancement has been regarded as an approach that focuses on formal features of the target language in the context of communication. A caveat is in order; certain forms may be noticed more than others, and it is possible that a form is noticed perceptually but not linguistically. However, this does not rule out the possibility that learners are more likely to attend to perceptually salient forms (Barcroft \& VanPatten, 1997; Rosa \& O'Neill, 1998).

As an unobtrusive focus on form attention-catching device, TE refers to the physical manipulations exercised on certain aspects of the text (Doughty \& William, 1998). The physical manipulation may be realized in the form of a change in the font size, using bolding or italics, highlighting or a combination of these. The basic assumption behind the use of TE is that the saliency of target items brought about by TE renders them more noticeable and learnable.

A number of studies have examined the effectiveness of TE on noticing and learning of the target structures of a second language and come up with mixed results. Jourdenais et al. (1995) studied the effects of TE on noticing and learners' processing of target items. In their study, the enhancement group was provided with a text in which the target items had been made typographically highlighted. The control group was presented with the same reading unenhanced. The results showed that the learners in the enhancement group outperformed those in the control group in terms of both noticing and production of the forms in question. Doughty (1991) found that the saliency operationalized by applying certain TE manipulations on the target forms led to increased noticing on the part of the learners. However, as the learners in the experimental groups were, in addition to TE, exposed to other techniques such as rephrasing and rule presentation, the gains made by the learners could merely indirectly be attributed to the effects of TE. Alanen (1995) compared the effects of TE with those of explicit instruction on the acquisition of French locative features and consonant gradation. The participants were assigned to four groups; a group that received textual enhancement only, a group exposed to explicit instruction of the target form, a group provided with both types of treatment, and a control group. The results indicated that the TE group outperformed the other groups.

White (1998) studied the effects of TE on both noticing and acquisition of third person singular possessives in English. The French-speaking participants in the study received ten hours of instruction in which the learners were exposed to reading texts with enhanced target forms. The results suggested that TE can lead to increased noticing, but that it does not necessarily lead to learners' development of knowledge of the target structures. Izumi (2002) also found no significant difference between the enhanced and unenhanced group in terms of the comprehension of input containing relative clauses, although the learners in the enhancement group were shown to have had increased noticing of the target forms.

\subsection{Advance Organizers}

The idea of the use of advance organizers in education in general was first proposed by Ausubel (1961) to describe the process of taking a leap from the known to the unknown. He defined the term as "appropriately relevant and inclusive introductory materials that are maximally clear and stable... introduced in advance of the learning material itself, used to facilitate establishing a meaningful learning set"(p. 268). He further claimed that 
advance organizers can have facilitative effects in improving the retention of to-be-learnt materials. Although the origin of the concept can be traced in the discipline of Educational Psychology, it was not limited there, and was also subjected to a number of studies in the discipline of second language acquisition (SLA) (e.g., Chung \& Huang, 1998; Hanley et al., 1995; Herron et al., 1998; Kirkman \& Shaw, 1997; Alvermann, 1981; Denner \& Rickards, 1987; Glover, 1989; King, 1992; Osman \& Hannafin, 1994).

In SLA literature, advance organizers may be said to have operationally deviated from what Ausuble had in mind in that they are not necessarily inclusive of the to-be-learnt material, and in that they are characterized by a number of forms ranging from descriptions to pictures and even teacher talk. Herron (1994) is a case in point which explored the effects of the use of Description + video advance organizers, and came up with the result that the $\mathrm{AO}$ group outperformed the control group on tests of comprehension and retention targeting the information imparted to them in the videos.

Herron et al. (1995) was another attempt to put to empirical investigation the effectiveness of advance organizers in which AOs were in the form of either Description + Pictures or Description only. The beginner foreign language learners in the description only condition were exposed to a mere description of the major scenes of the videos, while the description + pictures group received a description in addition to a number of pictures. The results showed that the combination of pictures with description proved to be a more effective advance organizer in that the learners outperformed the picture only condition.

Hanely et al. (1995) exposed one of the groups in their study to a video condition and the other to a pictures plus teacher narrative condition. The findings of their study indicated that the learners who had received video AOs outperformed those placed in the picture pus teacher narrative condition. Ginther (2002) also examined the effects of visual advance organizers on learners' listening comprehension. Using a series of tasks to evaluate the learners' listening comprehension, the study suggested that the use of visuals corresponding to the audio portion of the learning task could lead to substantial gains on the task performance. Finally, Vandergrift (2004) suggested that content-related AOs could conceivably be more effective than context-related AOs.

Previous studies on advance organizers in SLA have mainly been concerned with the effects of these tools on learners' listening comprehension. A research lacuna requiring further investigation concerns the effectiveness of advance organizers on the acquisition of the grammar of a second language. Given the fact that grammar instruction has come to be recognized as a full-fledged principle in SLA research and pedagogy, advance organizers, as a tool that can potentially lead to more accuracy on the part of the learners, call for empirical research, and a comparison of the effectiveness of this tool with conventional focus on form approaches such as textual enhancement might shed some light on the workings of the EFL learners' attentional system. The present study, therefore, is an attempt in that direction.

The advance organizers utilized in the current study were of two types; intralingual or interlingual. Intralingual advance organizers are characterized as those which draw the learners' attention to a relevant item in the second language, and interlingual advance organizers as those which are intended to induce the learners' attention to a form in the learners' mother tongue. If the instructional material or the teacher, for example, introduces a number of grammatically equivalent items, if any, from the learners' mother tongue, to the learners prior to the presentation of the to-be-learnt material, the pre-grammaring stage can be referred to as an interlingual advance organizer for the grammar structure in question. On the other hand, the instructional material could begin with an introduction of a structure from the second language which are in some way relevant to the target structure and then move on to present the to-be-learnt material in which case the exposure can be said to be an example of intralingual advance organizers for the intended target structure. It should be noted that the item of being referred to in the mother tongue or the target language ought to meet the relevance condition, meaning that the item should be in some way relevant to the target structure. In other words, it could be inclusive of, contrasting with or similar to an item in the target language intended to be acquired by the learners. 
The comparative effects of advance organizers vs. input enhancement on the acquisition of English passivization

To seek answers to the questions posed in the study as to the effects of advance organizers as opposed to textual enhancement in the development of grammatical knowledge of passive structures, the following research questions were formulated:

1. Do Inter-AOs lead to the development of grammatical knowledge on the part of L2 learners?

2. Do Intra-AOs lead to the development of grammatical knowledge on the part of L2 learners?

3. Does the use of TE lead to the development of grammatical knowledge on the part of L2 learners?

4. How are the effects of Inter-AOs and Intra-AOs compared with those of TE when it comes to the development of grammatical knowledge?

\section{Materials and Method}

\subsection{Participants}

A pool of 80 male intermediate Persian-speaking learners (aged from 15 to 20) enrolled in Iran Language Institute (ILI) EFL courses at Shahrekord branch were selected to enter the study. The learners had already been screened out by a placement test along with an interview administered by the ILI officials, and randomly assigned to 4 intact homogeneous classes. To ensure that the participants were also homogeneous in terms of the knowledge of the target structures of the study, a pretest was administered which consisted of items testing a number of grammatical structures including passive sentences. The purpose of the inclusion of items testing structures other than passive sentences was that they would act as distracters preventing the target structure to be given away. The results of the pretest as shown in Table 1 indicate that the learners were also homogenous with regard to their knowledge of passive sentences. The pretest was administered to 20 other intermediate learners who were with at the same level of language proficiency of language in general and of the target structures in particular to the would-be participants in the study, to obtain assurance that it enjoyed a desirable index of reliability. Internal consistency was measured using Cronbach's formula, and the value turned out to be 0.74.

\section{Table 1}

Results of Pretest

\begin{tabular}{lcccc}
\hline & $N$ & Mean & $S D$ & $S E$ \\
\hline IntraAO Group & 20 & 1.35 & .93330 & .20869 \\
InterAO Group & 20 & 1.45 & 1.09904 & .24575 \\
TE Group & 20 & 1.30 & .97872 & .21885 \\
Control Group & 20 & 1.50 & .88852 & .19868 \\
\hline
\end{tabular}

\subsection{Materials}

The target structure introduced to the learners was the passive voice. The reason for the selection of passive sentences to be exposed to the learners was that passivization seemed to be unknown to the learners. The pretest results showed that the learners possessed mastery over 6 English tenses; simple present, present progressive, simple past, past progressive and past perfect. Therefore, the passive forms of these six tenses became the target structures of the study. The presentation of the passive voice of each of the tenses was assigned to 5 powerpoint presentations manipulated in accord with the purpose of the research. Each of the 5 powerpoint presentations assigned to the same tense used different reading texts, but they were parallel in that they all targeted the presentation of a single passive form corresponding with the tense in question.

The powerpoint presentations for the Inter-AO group consisted of two slides. The first slide contained 5 
Persian passive sentences, and the second slide contained a reading passage with 5 passive sentences embedded in it. The purpose for the inclusion of the first slide was to prime the learners to the target structure. The powerpoint presentations for the Intra-AO group also consisted of two slides. The first slide displayed 5 English active sentences each followed with its passive counterpart. The active sentences in the first slide were operationalizations of the Intra-AOs. The second slide was exactly the same as the second slide designed for the Inter-AO group. As for the learners in the TE group, the powerpoint presentations contained a single slide displaying the same reading passage the other two groups were exposed to, with the difference that the passive structures in the text had been textually enhanced through highlighting. Having been constructed, the powerpoint presentations were submitted to 3 expert judges with PhD degrees in Applied linguistics who were asked to point out anything that might have gone unnoticed by the researchers. Accordingly, a number of modifications in line with the judges' comments were made to the slides.

The testing instrument used to tap into the participants' knowledge at the outset of the study was a grammar test consisting of two subsections. The first subtest included 10 items which were of a Truth-value Judgment nature (TVJT), i.e., the learners were presented with 2 reading texts followed by 10 questions intended to gauge the learners' comprehension of the events referred to in the text. The questions were constructed in such a way that a correct response would require full understanding of the use of passive sentences in the text. The second measuring instrument was a Grammaticality Judgment Test (GJT) consisting of 30 items requiring the participants to judge whether a given sentence sounds grammatical or not. A parallel test, with the Cronbach's reliability value of 0.71 , consisting of the same two TVJT and GJT subsections were, in addition, designed to be used as posttest.

\subsection{Procedure}

Prior to the beginning of the research, the learners were asked to give their consent regarding the allocation of time to the research. The ILI officials were also consulted and asked to sign a consent form. The learners attended their regular classes 3 times a week, and the treatment phase of the study involved 30 sessions lasting 10 weeks. The first 15 minutes of each regular session was allotted to the treatment phase in which one of the researchers displayed the powerpoint presentations, and asked the students to read the text appearing on each slide. For each tense, five in-a-row 15-minute sessions were assigned to the passive voice. The powerpoint presentations created to introduce the passive form of a single tense had different words and reading texts within them. As the aim of the research was investigating the effectiveness of the different types of exposure, the researcher merely displayed the powerpoint slides and avoided any sort of intervention. It should be noted that the reading passage exposed to the learners was the same across the 4 groups. Below is a summary of what each group received as input in the treatment phase.

Inter-AO group: For each of the 6 tenses, 5 powerpoint presentations containing Persian passive sentences followed with corresponding English passive sentences plus a reading passage containing passive sentences. Intra-AO group: For each of the six tenses, 5 powerpoint presentations containing active English sentences followed with corresponding passive sentences plus a reading passage containing passive sentences repeated five times for each tense but using different words and reading texts. TE group: For each of the six tenses, 5 powerpoint presentations containing a reading passage with passive structures highlighted throughout. Control group: For each of the six tenses, 5 powerpoint presentations containing reading texts with the target structures unenhanced.

\section{Results}

The descriptive statistics for the posttest results have been displayed in Table 2. As can be seen in the table, all the groups except for the control group have made substantial progress on their performances on the posttest compared with the pretest results shown in Table 1, with the Inter-AO group gaining the maximum results and the control group coming in at the last rank. As can be seen in the table, the mean of the Inter-AO group is 17.35, 
The comparative effects of advance organizers vs. input enhancement on the acquisition of English passivization higher than that of the other groups. Also the standard deviations in the three experimental groups are fairly close.

Table 2

Results of Posttest

\begin{tabular}{lcccc}
\hline & $N$ & Mean & $S D$ & $S E$ \\
\hline InterAO Group & 20 & 17.35 & 1.59852 & .35744 \\
IntraAO Group & 20 & 15.8 & 1.96281 & .43890 \\
TE Group & 20 & 13.4 & 1.46539 & .32767 \\
Control Group & 20 & 1.55 & .99868 & .22331 \\
\hline
\end{tabular}

In order to find out if the comparative effects of the different types of grammar presentation on the grammatical knowledge of the learners, in addition to being productive, also reached a level of significance, a one-way ANOVA was run on the posttest results. The results of the posttest have been depicted in Table 3. The results of the ANOVA as displayed in Table 3 show that the groups are significantly different from one another after the treatment $(F=430.52, p<0.05)$.

Table 3

Posttest Results

\begin{tabular}{lccccc}
\hline & Sum of Squares & $d f$ & Mean Square & $F$ & Sig. \\
\hline Between Groups & 3084.450 & 3 & 1028.150 & 430.52 & .000 \\
Within Groups & 181.500 & 76 & 2.388 & & \\
Total & 3265.950 & 79 & & & \\
\hline
\end{tabular}

A post hoc pairwise comparison was also conducted to indicate the difference between the groups. The results of the post hoc can be seen in Table 4. The results show that the Inter-AO group outperformed the other groups, and that all the other groups performed significantly differently from one another at the probability level of 0.05 . As can be seen in Table 4, the results of the Inter-AO group on the posttest were significantly better than those of the Intra-AO group (mean difference $=1.55, p<0.05$ ). Compared with the TE group, the Inter-AO group outperformed with a mean difference of 3.95. The mean difference between the performance of the TE group and that of the control group was 15.8 .

The post hoc comparisons also indicated that the Intra-AO group, which came in second in the current experiment, did better than the other two groups, and the difference turned out to be statistically significant. In comparison with the TE group, the Intra-AO group did better (mean difference $=2.4$ ). It also outperformed the control group with a mean difference of 14.25. The difference between the performances of the TE group compared with the control group indicated that the TE group did significantly better with the considerably large difference of 11.85. The results of the performances of the groups on the posttest have been displayed in Table 4 .

\section{Table 4}

Posttest Results Scheffe

\begin{tabular}{llcrc}
\hline & & Mean Difference & Std. Error & \multicolumn{1}{l}{ Sig. } \\
\hline Inter-AO & Intra-AO Group & $1.55^{*}$ & .48869 & .023 \\
Group & TE Group & $3.95^{*}$ & .48869 & .000 \\
& Control Group & $15.8^{*}$ & .48869 & .000 \\
Intra-AO & TE Group & $2.4^{*}$ & .48869 & .000 \\
Group & Control Group & $14.25^{*}$ & .48869 & .000 \\
TE Group & Control Group & $11.85^{*}$ & .48869 & .000 \\
\hline
\end{tabular}

Note. *. The mean difference is significant at the 0.05 level. 


\section{Discussion and Conclusion}

The findings of the study hinted at the idea that the use of advance organizers could potentially enhance learning in a foreign language context (Chung \& Huang, 1998, Hanley et al., 1995, Herron, 1994, and Herron et al., 1998). The first research question posed in the study concerned the effects of inter-AOs on the development of grammatical knowledge regarding the formation of passive sentences. The results of the posttest suggest that the inter-AO group gained substantial knowledge of the target items, outperforming the other groups with a significant difference. This could be attributed to the possibility that the learners in this group embarked on the learning path as they were reminded about equivalent Persian passive sentences through advance organizers, and it could be argued that EFL learners possibly carry a considerably strong cross-linguistic backdrop that paves the way for them to acquire the target structure more effectively. In other words, the learners in the Inter-AO group have possibly drawn on the repertoire of their first language grammar knowledge and from there made a move to the unknown target forms. The idea that the use of the learners' first language could help learners move from the known to the unknown has been strongly espoused in the literature (Atkinson, 1987; Campbell, 1997; Chambers, 1992; Garret et. al., 1994; Mclaughlin, 1986). As Campbell (1997) maintains, teaching, and by extension learning, from the known to the unknown in general education is translated into proceeding from the mother tongue to the target language in foreign language teaching. The effects of the Inter-AOs in the current study appear to substantiate this claim, lending evidence to Ausuble's claim that meaningful learning revolves around the integration of new knowledge with already-existing schemata and the transfer of the knowledge the students possess to new contexts (Fakharzadeh, Youhanaee, \& Nejadansari, 2013).

The fact that the Inter-AO group outperformed the Intra-AO group could be due to the possibility that the learners in the Inter-AO condition were more cognitively primed to the to-be-learnt material than were those in the Intra-AO condition. In other words, it is possible that EFL learners at an intermediate level of language proficiency are more familiar with the structures in their mother tongue than they are with those in the second language, and that the inter-AO materials presented to them primed them effectively enough for learning to come about.

The findings of the study also indicated that both Inter-AO and Intra-AO groups significantly outperformed the TE group. It could be argued that whereas TE merely draws the learners' attention to the target structure in question, advance organizers create an attentional system that goes one step further than the attention-drawing phase and sets up links between the already-known structures and the new ones. That is, one could conceive of attention mechanism as either a one-dimensional self-sufficient system, or a multi-dimensional one in which knowledge brought about as a result of attention to one item is fostered by creating links between the new item and the ones the learners are already familiar with. The fact that TE has been mostly documented to have led to increased noticing and failed to translate into language development on the part of EFL learners has already been reported as a finding in a number of studies (White, 1998; Izumi, 2002). The reason for this failure could be argued to have something to do with the merely one-dimensional attentional system that it possibly creates. It remains to be seen what effects would be accrued if TE was accompanied with output-based activities. It is possible that incorporating output-based activities to be used along with TE into grammar instruction could enhance the results, though we are still left with the question what cognitive links are created in this fashion. It should, of course, be pointed out that TE did result in the development of the target structure in the current study, but the results faded into insignificance compared with the effects of AOs.

Given that the provision of a cognitive known-to-the-unknown peg has appeared to be useful in the current study, one of the implications of the study is that a case can be made for the incorporation of pre-grammaring activities into EFL syllabi and teaching procedure. It is not an aloof concept to the SLA researchers as there is a pile of research studies which unequivocally underscore the importance of a pre-listening and a pre-reading stage. In the same vein, it could be argued that grammaring, as coined by Larson-Freeman (2003), requires its own pre-grammaring phase in which the learners are primed to the to-be-learnt target grammatical points. One of the potentially productive candidates for this pre-grammaring stage could be the use of interlingual and intralingual 
The comparative effects of advance organizers vs. input enhancement on the acquisition of English passivization advance organizers. In other words, incorporating pre-grammaring activities in general, and items from the learners' mother tongue in particular, into instruction could conceivably lead to remarkable gains, providing suitable grounds for the acquisition of second language grammar.

Materials developers would also need to take into consideration the idea that learning the grammar of a second language would be remarkably facilitated if the textbooks incorporated points and examples that the learners could relate to. Also, although input enhancement did turn out to produce significant effects on the learners' acquisition of target items, it merely focused on one particular item at a time, and failed to create links between the new items and those already known to the learners. Teachers and materials developers would do well if they used a combination of textual enhancement and advance organizers to achieve maximum results. The learners would also benefit more from instruction if the use of advance organizers were delivered to them in the form of a strategy that they could employ on their own. If the learners were equipped with the use of advance organizers as a strategy, they would be able to fall back on their already-held schemata and make the learning task more manageable. It remains to be tested empirically if the use of this strategy could also help learners reduce their anxiety when faced with the challenges that learning the grammar of a second language could entail.

A number of caveats regarding the results of the study are in order. It should be pointed out that the study dealt only with intermediate learners. Further studies could be conducted to clarify whether the same findings could be substantiated with learners at different levels. Another point pertains to the form in which the AOs were presented to the learners. A potential research question concerns the idea of what results would have been obtained had the AOs been embedded in a reading passage or a video. A third caveat concerns the idea that not every second language structure could readily lend itself to AOs. The target structure itself could, in turn, impact the results. It is a potential hypothesis whether the effects of AOs are more or less the same if other structures were set as their target.

\section{References:}

Alanen, R. (1995). Input enhancement and rule presentation in SLA. In R. Schmidt (Ed.), Attention and awareness in foreign language learning (pp. 259-302). Honolulu: University of Hawaii Press.

Alvermann, D. E. (1981). The compensatory effect of graphic organizers on descriptive text. Journal of Educational Research, 75(1), 44-48.

Atkinson, D. (1987). The mother tongue in the classroom: A neglected resource. ELT journal, 41(4), 241-247. http://dx.doi.org/10.1093/elt/41.4.241

Ausubel, D. P. (1960). The use of advance organizers in the learning and retention of meaningful verbal material. Journal of Educational Psychology, 51(5), 267-272. http://dx.doi.org/10.1037/h0046669

Barcroft, J., \& VanPatten, B. (1997). Acoustic salience: Testing location, stress, and the boundedness of grammatical form in second language acquisition input perception. In W. Glass \& A. Perez-Leroux (Eds.), Contemporary perspectives on the acquisition of Spanish: Production, processing, and comprehension (pp. 109-121). Somerville, MA: Cascadilla Press.

Bialystok, E. (1994). Representation and ways of knowing: Three issues in second language acquisition. In N. Ellis (Ed.), Explicit and implicit learning of languages (pp. 549-569). London: Academic Press.

Bygate, M., Skehan, P., \& Swain, M. (Eds.). (2001). Researching pedagogic tasks: Second language learning, teaching, and testing. New York: Longman.

Campbell, I. (1997). Using English to support second language learning. Babel, 32(2), 10-14.

Celce-Murcia, M., Dörnyei, Z., \& Thurrell, S. (1997). Direct approaches in L2 instruction: A turning point in communicative language teaching? TESOL Quarterly, 31, 141-152. http://dx.doi.org/10.2307/3587979

Chambers, G. (1992). Teaching in the target language. Language Learning Journal, 6, 66-64. http://dx.doi.org/10.1080/09571739285200491

Chung, J. M., \& Huang, S. C. (1998). The effects of three aural advance organizers for video viewing in a foreign language classroom. System, 26, 553-565. http://dx.doi.org/10.1016/S0346-251X(98)00037-2

DeKeyser, R. (1998). Beyond focus on form: Cognitive perspectives on learning and practicing second language 
grammar. In C. Doughty \& J. Williams (Eds.), Focus on form in classroom second language acquisition (pp. 42-63). New York: Cambridge University Press.

Denner, P. R., \& Rickards, J. P. (1987). A developmental comparison of the effects of provided and generated questions on text recall. Contemporary Educational Psychology, 12, 135-146.

http://dx.doi.org/10.1016/S0361-476X(87)80047-4

Doughty, C. (1991). Second language instruction does make a difference: Evidence from an empirical study of SL relativization. Studies in Second Language Acquisition, 13(4), 431-469. http://dx.doi.org/10.1017/S0272263100010287

Doughty, C. (2001). Cognitive underpinnings of focus on form. In P. Robinson (Ed.), Cognition and second language instruction (pp. 206-257).Cambridge University Press. http://dx.doi.org/10.1017/CBO9781139524780.010

Doughty, C., \& Williams, J. (1998). Pedagogical choices in focus on form. In C. Doughty \& J. Williams (Eds.), Focus on form in classroom second language acquisition (pp. 197-261). New York: Cambridge University Press.

Ellis, R. (1985). Understanding second language acquisition. Oxford University Press.

Ellis, R. (1990). Instructed second language acquisition: Learning in the classroom. Oxford, UK: Blackwell.

Ellis, R. (1994). The study of second language acquisition. Oxford University Press.

Ellis, R. (1997). SLA research and language teaching. Oxford University Press.

Ellis, R. (2002a). Does form-focused instruction affect the acquisition of implicit knowledge? Studies in Second Language Acquisition, 24, 223-236. http://dx.doi.org/10.1017/S0272263102002073

Ellis, R. (2002b). The place of grammar instruction in the second/foreign curriculum. In E. Hinkel \& S. Fotos (Eds.), New perspectives on grammar teaching in second language classrooms (pp. 17-34). Mahwah, NJ: Erlbaum.

Fakharzade, M., Youhanaee, M., \& Nejadansari, D. (2014). Proceduralization, transfer of training and retention of knowledge as a result of output practice. International Journal of Research Studies in Language Learning, 3(2), 3-16. http://dx.doi.org/10.5861/ijrsll.2013.431

Fotos, S. (1993). Consciousness-raising and noticing through focus on form: Grammar task performance versus formal instruction. Applied Linguistics, 14, 385-407. http://dx.doi.org/10.1093/applin/14.4.385

Fotos, S. (1994). Integrating grammar instruction and communicative language use through grammar consciousness-raising tasks. TESOL Quarterly, 28(2), 323-351. http://dx.doi.org/10.2307/3587436

Garrett, P., Griffiths, Y., James, C., \& Scholfield, P. (1994). An experimental Investigation of effects on the attitudes and writing performance of bilingual UK schoolchildren. Journal of mutilingual and multicultural development, 15(5), 371-383. http://dx.doi.org/10.1080/01434632.1994.9994578

Ginther, A. (2002). Context and content visuals and performance on listening comprehension stimuli. Language Testing, 19(2), 133-167. http://dx.doi.org/10.1191/02655322021t225oa

Glover, J. A. (1989). Improving readers' estimates of learning from text: the role of inserted questions. Reading Research and Instruction, 28(3), 68-75. http://dx.doi.org/10.1080/19388078909557976

Hanley, J., Herron, C., \& Cole, S.P. (1995). Using video as an advance organizer to a written passage in the ELES classroom. The Modern Language Journal, 79(1), 57-66. http://dx.doi.org/10.1111/j.1540-4781.1995.tb05416.x

Harley, B., \& Swain, M. (1984). The interlanguage of immersion students and its implications for second language teaching. In A. Davies, C. Criper, \& A. P. R. Howatt (Eds.), Interlanguage (pp. 291-311). Edinburgh University Press.

Herron, C. (1994). An investigation of the effectiveness of using an advance organizer to introduce video in the foreign language classroom. The Modern Language Journal, 78(2), 190-198. http://dx.doi.org/10.1111/j.1540-4781.1994.tb02032.x

Herron, C., York, H., Cole, S. P., \& Linden, P. (1998). A comparison study of student retention of foreign language video: declarative versus interrogative advance organizer. The Modern Language Journal, 82(2), 237-247. http://dx.doi.org/10.1111/j.1540-4781.1998.tb01197.x

Izumi, S. (2002). Output, input enhancement, and the noticing hypothesis: An experimental study on ESL 
The comparative effects of advance organizers vs. input enhancement on the acquisition of English passivization

relativization. Studies in Second Language Acquisition, 24, 541-577.

http://dx.doi.org/10.1017/S0272263102004023

Jourdenais, R. (1998). The effects of textual enhancement on the acquisition of the Spanish preterit and imperfect. Unpublished Doctoral dissertation. Georgetown University, Washington, D. C.

King, A. (1992). Comparison of self-questioning, summarizing, and note taking-review as strategies for learning from lectures. American Educational Research Journal, 29(2), 303-323. http://dx.doi.org/10.3102/00028312029002303

Kirkman, G., \& Shaw, E.L. (1997). Effects of an oral advanced organizer on immediate and delayed retention. Paper presented at the 26th Annual Meeting of Mid-South Education Research Association (MSERA), Memphis, TN.

Lapkin, S., Hart, D., \& Swain, M. (1991). Early and Middle French immersion programs: French language outcomes. Canadian Modern Language Review, 48, 11-40.

Larsen-Freeman, D. (2003). Teaching language from grammar to grammaring. Boston:Thomson Corporation.

Larsen-Freeman, D., \& Long, M. (1991). An introduction to second language acquisition research. London: Longman.

Lightbown, P. (2000). Anniversary article: Classroom SLA research and second language teaching. Applied Linguistics, 21, 431-462. http://dx.doi.org/10.1093/applin/21.4.431

Long, M. (1983). Does second language instruction make a difference? A review of the research. TESOL Quarterly, 17, 359-382. http://dx.doi.org/10.2307/3586253

Long, M. (1988). Instructed interlanguage development. In L. Beebe (Ed.), Issues in second language acquisition: Multiple perspectives (pp. 115-141). Rowley, MA: Newbury House.

Long, M. (1991). Focus on form: A design feature in language teaching methodology. In K. DeBot, R. Ginsberg, \& C. Kramsch (Eds.), Foreign language research in cross-cultural perspective (pp. 39-52). Amsterdam: Benjamins.

Mclaughlin, J. (1987). Developing writing in English from mother tongue story telling. Language Issues, 1, 31-34.

Mitchell, R. (2000). Applied linguistics and evidence-based classroom practice: The case of foreign language grammar pedagogy. Applied Linguistics, 21, 281-303. http://dx.doi.org/10.1093/applin/21.3.281

Nassaji, H., \& Fotos, S. (2004). Current developments in research on the teaching of grammar. Annual Review of Applied Linguistics, 24, 126-145. http://dx.doi.org/10.1017/S0267190504000066

Osman, M. E., \& Hannafin, M. J. (1994). Effects of advance questioning and prior knowledge on science learning. Journal of Educational Research, 88(1), 5-13. http://dx.doi.org/10.1080/00220671.1994.9944829

Pienemann, M. (1984). Psychological constraints on the teachability of languages. Studies in Second Language Acquisition, 6, 186-214. http://dx.doi.org/10.1017/S0272263100005015

Pienemann, M. (1988). Determining the influence of instruction on L2 speech processing. AILA Review, 5 , 40-72.

Pienemann, M. (1999). Language, processing, and second language development: Processability theory. Amsterdam: Benjamins.

Rosa, E., \& O'Neill, M. (1998). Effects of stress and location on acoustic salience at the initial stages of Spanish L2 processing. Spanish Applied Linguistics, 2, 24-52.

Schmidt, R. W. (1990). The role of consciousness in second language learning. Applied Linguistics, 11(2), 129-158. http://dx.doi.org/10.1093/applin/11.2.129

Schmidt, R. W. (1993). Awareness and second language acquisition. Annual Review of Applied Linguistics, 13, 206-226. http://dx.doi.org/10.1017/S0267190500002476

Schmidt, R. W. (2001). Attention. In P. Robinson (Ed.), Cognition and second language instruction (pp. 3-32). Cambridge University Press. http://dx.doi.org/10.1017/CBO9781139524780.003

Sharwood Smith, M. (1981). Consciousness raising and second language learner. Applied linguistics, 2(2), 159-168. http://dx.doi.org/10.1093/applin/2.2.159

Sharwood Smith, M. (1991). Speaking to many minds: On the relevance of different types of language 
A'lipour, J., Youhanaee, M., \& Barati, H.

information for the L2 learner. Second Language Research, 7,118-132.

http://dx.doi.org/10.1177/026765839100700204

Truscott, J. (1998). Noticing in second language acquisition: A critical review. Second Language Research, 14, 103-135. http://dx.doi.org/10.1191/026765898674803209

Vandergrift, L. (2004). Listening to learn or learning to listen? Annual Review of Applied Linguistics, 24, 3-25. http://dx.doi.org/10.1017/S0267190504000017

White, J. (1998). Getting the learner's attention: A typographical input enhancement study. In C. Doughty \& J. Williams (Eds.), Focus on form in classroom second language acquisition (pp. 85-113). New York: Cambridge University Press. 